\title{
Antiguo Régimen, privilegios y modernidad política. El caso del ayuntamiento indio de Tlaxcala, $1815-1820$
}

Resumen. En 1815 se restauró el régimen colonial en la Nueva España, reinstalándose en Tlaxcala el ayuntamiento indio y el gobierno político y militar, tal y como funcionaban en 1793. Bajo el argumento de la continuidad de la guerra de Independencia, las autoridades virreinales sujetaron militar y políticamente a las corporaciones citadas, con las autoridades militares del Ejército del Sur, localizado en la vecina ciudad de Puebla. De esta manera, la autonomía que poseía la provincia de Tlaxcala se quebrantó, originando la reactivación de representaciones ante las autoridades novohispanas para evitar los continuos conflictos por el ejercicio político y militar. Lo que muestra el caso estudiado es que no estaban aún agotadas las formas de defensa y representación de los cuerpos políticos del Antiguo Régimen, frente a una modernidad política en naciente construcción.

Palabras clave: Privilegios, Antiguo Régimen, ayuntamiento de Tlaxcala, gobierno político-militar

\begin{abstract}
In 1815 colonial regime was restored in New Spain. Indian and political and military government were reinstalled in Tlaxcala, as it operated in 1793. Arguing the continuation of independence war, the viceroyal authorities held down military and politically the referred corporations by means of the Southern Army, stationed in the neighboring city of Puebla. The autonomy enjoyed by Tlaxcala province was thus broken, causing the resumption of representations made to New Spain authorities in order to avoid constant conflicts originated by political and military rule. The present study shows that, parallel to the early steps in the way of building a political modernity, still remained some Ancient Regime forms of defense and representation for political forces.
\end{abstract}

Keywords: Privileges, old regime, municipality of Tlaxcala, the political-military government 


\title{
Introducción
}

Desde hace ya varios años, una corriente historiográfica ha señalado que la guerra de Independencia en la Nueva España, entre 1810 y 1820, modificó en general las coordenadas de la participación política de los vecinos y ciudadanos de los pueblos y ciudades novohispanas. En opinión de Ortiz y Serrano:

\begin{abstract}
"La sociedad, que en el Antiguo Régimen estaba organizada a partir de los cabildos tanto de españoles como de naturales y demás corporaciones privilegiadas, adquirió una nueva dinámica basada en la igualdad en el uso de las armas; los vecinos de las ciudades, villas y localidades; adquirieron una amplia autonomía en materia tributaria y militar, y la estructura castrense se sobrepuso a la anterior estructura del gobierno provincial, con lo cual el intendente y los subdelegados perdieron el control territorial sobre los quehaceres administrativos de las ciudades, villas y localidades. A partir de esta nueva realidad de los gobiernos locales se fundaron, o mejor dicho se enraizaron los ayuntamientos gaditanos en la zona central de México". ${ }^{1}$
\end{abstract}

En contraste, este artículo busca argumentar que los nobles y caciques indios elegidos para formar parte del ayuntamiento de Tlaxcala entre 1815 y 1820, nuevamente bajo las reglas del Antiguo Régimen una vez derogada la Constitución de Cádiz de 1812, apelaron a la tradición de representación colonial ante las autoridades novohispanas, con la finalidad de defender sus privilegios. En el caso de la provincia de Tlaxcala durante los años citados, la lucha contra la insurgencia fue un argumento que justificó un conjunto de acciones del virreinato novohispano, uno de cuyos rasgos fue la supeditación de gobiernos provinciales a una comandancia realista, y por ende al jefe militar que la encabezaba. De esta manera, se suscitó un conflicto por la autonomía de gobierno entre el ayuntamiento indio y el gobierno político-militar encabezado este por un funcionario designado por el rey, frente a la comandancia del Ejército del Sur y los diferentes virreyes que se sucedieron en estos cinco años.

En plena guerra de independencia y a pesar de introducirse en años previos un modelo de prácticas políticas modernas con la Constitución de Cádiz, el caso estudiado muestra que no estaban aún agotadas las formas de defensa y representación de los cuerpos políticos del Antiguo Régimen. Estas se activaron cuando se quebrantaron sus privilegios, dándoles la oportunidad a los miembros del

${ }_{1}$ ORTIZ ESCAMILLA, Juan y SERRANO, Juan Antonio, Ayuntamientos y liberalismo gaditano, México, El Colegio de Michoacán, 2007, p. 12. 
Cabildo de actuar fundados nuevamente en la vigencia de los marcos normativos coloniales.

El resto de las secciones que comprenden el artículo abordan primero una reflexión historiográfica de los años 1815 a 1820, seguida de un apartado sobre los privilegios y la modernidad política en Tlaxcala en los años previos al período estudiado. Posteriormente, el artículo sigue las vicisitudes de un conflicto en el que, actuando conjuntamente el ayuntamiento indio de la ciudad de Tlaxcala y el gobierno político y militar de la provincia establecido en 1793 y encabezado por un funcionario español nombrado por el rey de España, se pronunciaron ante los virreyes de la Nueva España y los jefes militares de la comandancia poblana del Ejército del Sur contra la intervención política y administrativa ejercida por ésta, la cual violaba sus privilegios de autogobierno concedidos por el rey varios siglos atrás. No fue hasta mayo de 1820 que se reconoció parcialmente la autonomía del gobierno político y militar, "coincidentemente" con el restablecimiento la Constitución de Cádiz.

\section{Historiografía de la restauración del Antiguo Régimen en la Nueva} España, 1815-1820

Es importante destacar que hasta hace poco, en varios trabajos de evaluación historiográfica sobre las independencias en Iberoamérica y la Nueva España, el periodo que va de la restauración del Antiguo Régimen colonial en 1815 a la renovación de la Constitución de Cádiz en mayo de 1820 no es señalado particularmente como un conjunto específico de años que pareciera tener problemas relevantes de estudio sobre la Independencia. ${ }^{2}$ Incluso muchos trabajos que son interpretaciones generales del proceso prácticamente pasan de largo dicho periodo y dan un salto de la Constitución de Cádiz (fines de 1812 y su vigencia hasta 1814), a los años de la restauración del régimen gaditano en 1820.3 Este es el caso también de diversos estudios que analizan regiones, provincias o ayuntamientos. 4

\footnotetext{
2 CHUST, Manuel y SERRANO, José Antonio, "Un debate actual. Una revisión necesaria", José Antonio SERRANO y Manuel CHUST (ed.), Debates sobre las independencias iberoamericanas, Madrid, AHILA, 2007, pp. 9-25; ÁVILA, Alfredo y GUEDEA, Virginia (coord.), La independencia de México. Temas e interpretaciones recientes, México, IIH-UNAM, 2007; ANNINO, Antonio y ROJAS, Rafael, La independencia. Los libros de la patria, México, CIDE-FCE, 2008.

3 Véase por ejemplo HAMNETT, Brian, Raíces de la insurgencia en México, Historia regional 17501824, México, FCE, 1990; HERNÁNDEZ CHÁVEZ, Alicia, La tradición republicana del buen gobierno, México, FCE-El Colegio de México, 1993; ÁVILA, Alfredo, En nombre de la nación. La
} 
Ahora bien, si se revisa la diversa producción historiográfica que aborda dicho periodo, cuyo objetivo es analizar el proceso más amplio de la guerra de independencia, los años de 1815 a 1820 son caracterizados como un período en el que ocurren dos cuestiones importantes. Una de ellas es el restablecimiento de Fernando VII en España y con ello la derogación de la constitución de Cádiz, así como el conflicto y la discusión que esto causó en los grupos criollos y españoles de las colonias americanas, entre ellas Nueva España, en torno a aceptar o no nuevamente al régimen español. 5

Un segundo tema de referencia para los años de 1815 a 1820, es de carácter militar, en tanto proseguía la lucha entre insurgentes y realistas. En términos generales los trabajos de Christon I. Archer han abordado esta problemática haciendo un mayor énfasis en el lado realista y cómo este fue retomando el control de Nueva España. ${ }^{6}$ Por su parte, Ortiz ha explorado mayormente la organización militar de la

formación del gobierno representativo en México (1808-1824), México, CIDE-Taurus, 2002; CHUST, Manuel, "Legitimidad, representación y soberanía: del doceañismo monárquico al republicanismo federal mexicano", Brian F. CONNAUGHTON (coord.), Poder y legitimidad en México en el siglo XIX. Instituciones y Cultura Política, México, UAM-Iztapalapa-CONACYT-Miguel Ángel Porrúa, 2003, pp. 209-247; ROJAS, Rafael, La escritura de la independencia. El surgimiento de la opinión pública en México, México, CIDE-Taurus, 2003; CHUST, Manuel y FRASQUET, Ivana, "Soberanía hispana, soberanía mexicana: México, 1810-1824", Manuel CHUST (coord.), Doceañismos, constituciones $e$ independencia. La constitución de 1812 y América, España, Fundación MAPFRE, 2006, pp. 169-237.

4 Algunos casos de estudio son: GUZMÁN PÉREZ, Moisés (coord.), Cabildos, repúblicas y ayuntamientos constitucionales en la independencia de México, México, Instituto de Investigaciones Históricas de la Universidad Michoacana de San Nicolás de Hidalgo-Gobierno del Estado de Michoacán, 2009; GUARDINO, Peter, Campesinos y política en la formación del estado nacional en México, Guerrero, 180o-1857, Stanford University Press-Gobierno del Estado de Guerrero, 1996; ESCOBAR, Antonio, "Del gobierno indígena al ayuntamiento constitucional en las huastecas hidalguense y veracruzana, 1780-1853", Mexican Studies/Estudios Mexicanos, University of California-UNAM, vol. 12, núm. 1, invierno 1996, pp. 1-26; JUÁREZ, Carlos, "Un ayuntamiento mexicano ante la guerra de Independencia: El caso de Valladolid de Michoacán, 1810-1821”, Historias, INAH, abril-septiembre de 1994, núm. 32, pp. 45-53; DUCEY, Michael T., "Village, nation, and constitution: insurgent politics in Papantla, Veracruz, 1810-1821", Hispanic American Historical Review, Duke University Press, vol. 79, núm. 3, 1999, pp. 463-493; BELLINGERI, Marco, "Cabildos en Yucatán. La conformación de las instituciones liberales", Othón BAÑOS, (comp.), Liberalismo, actores y política en Yucatán, México Universidad Autónoma de Yucatán, 1995, pp. 83-102.

5 RODRÍGUEZ O. Jaime, La independencia de la América española, México, FCE-El Colegio de México, 1998 y El proceso de la Independencia de México, México, Instituto de Investigaciones Dr. José María Luis Mora, 1992; VÁZQUEZ, Josefina Zoraida, "De la crisis monárquica a la independencia (1808-1821)", Josefina Zoraida VÁZQUEZ (coord.), Interpretaciones de la independencia de México, México, Nueva Imagen, 1997, pp. 9-32; CHUST, Manuel, De la revolución hispana a la revolución española: claves del doceañismo gaditano, 1808-1837, México, CONACYT-Universidad de Zacatecas, 2000.

${ }^{6}$ Tres ejemplos son: "La revolución militar de México: estrategia, tácticas y logísticas durante la guerra de Independencia, 1810-1821", VÁZQUEZ, J. Z. (coord.), Interpretaciones... ob. cit., pp. 123-176; "En busca de una victoria definitiva: el ejército realista en Nueva España, 1810-1821", Marta TERÁN y José Antonio SERRANO (ed.), Las guerras de independencia en la América española, México, El Colegio de Michoacán-INAH-Universidad Michoacana, 2002, pp. 423-438 e "Historia de la guerra: las trayectorias de la historia militar en la época de la independencia de Nueva España”, Alfredo ÁVILA y 
insurgencia de 1810 a 1821, señalando cómo la autonomía alcanzada por el control castrense de pueblos y ciudades fomentó una cultura política de participación en los asuntos de gobierno, sobre todo a partir de la posibilidad de erigir ayuntamientos constitucionales bajo las reglas de la Constitución de Cádiz de 1812. No obstante, los trabajos de Ortiz, a pesar de explorar la década de la lucha insurgente no examinan con especificidad qué sucedió con la restauración del régimen colonial en 1815, posterior al impulso que entre 1812 y 1814 se dio a los vecinos y ciudadanos de los pueblos para participar políticamente.7

El tratamiento que Ortiz le da al tema de la participación política de los pueblos entre 1810 y 1820 ante el impacto de la guerra de Independencia y la Constitución gaditana de 1812 analiza un tema que en las últimas dos décadas ha sido un boom en el estudio del proceso de independencia, visto desde el balcón de la modernidad política y su papel en la construcción del estado-nación. ${ }^{8}$ Así, temas como el liberalismo gaditano, la ciudadanía, la representación, la creación de ayuntamientos y las elecciones; forman parte ya de un conjunto de análisis articulados. Como indican Chust y Serrano:

“... el liberalismo gaditano impregnó un amplio espectro del proceso de construcción de los estados-nación. Y su trascendencia no se limitó sólo a la participación de sus diputados, sino a la aplicación de sus decretos, a la politización de la sociedad, a la interacción que provocaron sus ondas sísmicas... a los procesos electorales que desencadenaron, a la importancia en la organización de ayuntamientos, milicias nacionales..."9

\footnotetext{
Virginia GUEDEA, ob. cit., pp. 145-162. Para un caso de estudio regional sobre el ejército realista en Puebla y Tlaxcala, puede verse BARBOSA RAMÍREZ, Jesús, Súbditos, ia las armas! La respuesta del ejército realista al movimiento de Independencia en la región Puebla-Tlaxcala, 1808-1821, México, BUAP, 2009.

7 ORTIZ, Juan, "La guerra de Independencia y la autonomía de los pueblos", VÁZQUEZ, Josefina Zoraida (coord.), Interpretaciones..., ob. cit., pp. 177-214; ORTIZ, Juan, Guerra y gobierno. Los pueblos y la Independencia de México, México, Instituto Mora-El Colegio de México-Universidad Internacional de Andalucía-Universidad de Sevilla, 1997.

8 Véase ROJAS, Rafael, "Historiografía de la independencia (siglo XIX)", Antonio ANNINO y Rafael ROJAS, La independencia. Los libros de la patria, México, CIDE-FCE, 2008, pp. 132-137. De GUEDEA, Virginia, "La nueva 'historia política' y el proceso de independencia novohispano", Guillermo PALACIOS (coord.), Ensayos sobre la nueva historia política de América Latina, siglo XIX, México, El Colegio de México, 2007, pp. 95-110; "La historia política sobre el proceso de independencia”, Alfredo ÁVILA y Virginia GUEDEA (coord.), La independencia de México..., ob. cit., pp. 41-64. Y de la misma autora citada, en coautoría con AVILA, Alfredo; "De la independencia nacional a los procesos autonomistas novohispanos: balance de la historiografía reciente", José Antonio SERRANO, y Manuel CHUST (ed.), Debates..., ob. cit., pp. 255-276.

9 CHUST y SERRANO, "Un debate actual...", ob. cit., p. 23.
} 
No obstante y ante esta afirmación, el mismo Chust -uno de los principales estudiosos de la Independencia en América-, calificando al periodo de 1815 a 1820 como la tercera fase del movimiento independiente con la restauración de la monarquía absolutista en la Nueva España, reconocía en un texto del 2010 que aún faltaban “... más estudios sobre el periodo, que se revela fundamental”. ${ }^{10} \mathrm{La}$ respuesta llegó en un texto del 2014 coordinado por Serrano, donde se presentan diversos trabajos que discuten para el caso de la Nueva España, los cambios y permanencias del periodo 1815 a 1820, en relación con los últimos años del periodo colonial, la guerra de Independencia y los primeros años constitucionalistas de Cádiz. ${ }^{11}$ Los hallazgos del libro fueron variados y se plantearán aquí sólo algunos ejemplos.

En relación con el impacto de Cádiz, uno de los debates generados en la provincia de Zacatecas fue acerca de la soberanía del Rey de España, siendo los funcionarios de la restauración quienes defendieron la soberanía absoluta, mientras que las élites criollas señalaban la necesidad de compartir el poder en las instituciones coloniales. Finalmente prevaleció el criterio absolutista. ${ }^{12}$ Por otra parte, en una valoración en conjunto para la Nueva España, Serrano desarrolla dos argumentos. ${ }^{13}$ De acuerdo con este investigador entre 1815 y 1820, con el regreso de Fernando VII los funcionarios reales buscaron darle continuidad a diversas medidas tomadas durante el apogeo del reformismo borbónico de fines del siglo XVIII. Así, con el éxito alcanzado en el ámbito de los impuestos, la limitación de la autonomía de los señoríos indígenas y la desaparición de numerosos gremios; para Serrano “... todas estas medidas y circunstancias permitieron que Fernando VIII y con él muchos de los funcionarios reales fortalecieran la preeminencia regia frente a las corporaciones." $14 \mathrm{Si}$ bien en el ámbito de la impartición de justicia por parte del monarca, no logró mantener dicho atributo al ser cuestionado este por diversos estamentos y corporaciones novohispanas.

\footnotetext{
10 CHUST, Manuel, "De rebeliones, independencias y, si acaso, revoluciones", Antonio ANNINO (coord.), La revolución novohispana, 1808-1821, México, Fondo de Cultura Económica, 2010, p. 487. ${ }^{11}$ SERRANO ORTEGA, José Antonio (coord.), El sexenio absolutista, los últimos años insurgentes. Nueva España (1814-1820), México, El Colegio de Michoacán, 2014.

12 ESCOBEDO DELGADO, Martín, "Soberanía y representación. Conceptos fundamentales en el discurso político del Ayuntamiento de Zacatecas (1808-1821)", J. A. SERRANO ORTEGA, (coord.), El sexenio absolutista..., 2014, pp. 159-190.

13 SERRANO ORTEGA, José Antonio, "Las herencias ilustradas y gaditanas en tiempos del absolutismo. Nueva España (1814-1819)”, J. A. SERRANO ORTEGA (coord.), El sexenio absolutista..., ob. cit., pp. 191-228.

14 Ibid., p. 17.
} 
En el caso de la Intendencia de San Luis Potosí, a partir del inicio de la guerra de Independencia en 1810 los militares se convirtieron en actores sociopolíticos relevantes en la intermediación con otros actores de la Intendencia e instituciones de gobierno. Esto no cambió con la restauración del régimen colonial en 1815, de tal forma que el ayuntamiento de la capital potosina y sus miembros poseedores de jerarquía sociopolítica y económica, tuvieron que relacionarse con los militares de la Intendencia para gobernar. ${ }^{15}$

Finalmente, cabe mencionar el trabajo de Arrioja, quien con su estudio sobre el repartimiento de mercancías en Villa Alta, Oaxaca, demuestra que con la reinstalación del absolutismo se reintrodujo un mecanismo tradicional de compra y venta de productos agrícolas y manufactureros dominado por las élites económicas oaxaqueñas, obligando a los indígenas a sujetarse en la compra de insumos determinados por aquéllas y de igual forma a la venta de los productos que obtenían del campo. ${ }^{16}$

En su conjunto, estos aspectos revelados por estudios sobre el período en examen muestran diversos resultados y grados de complejidad, siendo en varios casos un regreso al Antiguo Régimen para darle continuidad a las políticas borbónicas, en otro abriendo la discusión entre diferentes sectores sobre temas nodales del absolutismo como la soberanía y la justicia, así como los efectos socioterritoriales de la guerra de Independencia, al involucrar nuevos actores, en este caso militares, en las jerarquías sociopolíticas y tareas de gobierno.

\section{Como bien señala Serrano:}

“...en los años que corren entre 1814 y 1820 se transformaron o de plano se extinguieron instituciones antiguas y se extendieron procesos históricos abiertos ya desde finales del siglo XVIII, y a partir [de] 1810. Fue un periodo histórico muy movido, más que uno marcado por la inmovilidad." ${ }^{17}$

15 BERNAL RUIZ, Graciela, "El mandato de su majestad y las circunstancias locales. La reinstalación del absolutismo en San Luis Potosí”, J. A. SERRANO ORTEGA (coord.), El sexenio..., ob. cit., pp. 275301.

${ }_{16}$ ARRIOJA DIAZ, Luis Alberto, "La experiencia absolutista en una subdelegación novohispana: Villa Alta (Oaxaca)", J. A. SERRANO ORTEGA, (coord.), El sexenio..., ob. cit., pp. 301-330.

${ }_{17}$ SERRANO ORTEGA, J. A (coord), El sexenio..., ob. cit., p. 22. 
En la siguiente sección del artículo se pondrá de manifiesto, de hecho, que en el caso de Tlaxcala no sólo fueron procesos históricos gestados en el último cuarto del siglo XVIII, sino inclusive provenientes de siglos atrás, en la medida que planteaban la defensa de privilegios otorgados desde el siglo XVI, los cuales le daban cohesión y sentido a la provincia de Tlaxcala gobernada por caciques y nobles indios.

\section{Privilegios, modernidad política y guerra de Independencia en Tlaxcala}

La provincia de Tlaxcala, y la ciudad del mismo nombre que era la sede de un ayuntamiento indio y asiento del gobernador español nombrado para ella, se localizaban en la región geográfica del centro de la Nueva España, al oriente de la Ciudad de México y al norte de la ciudad española de Puebla. Era una provincia predominantemente indígena, que desde el siglo XVI gobernaba un ayuntamiento indio, producto del privilegio conferido por el Rey de España a los tlaxcaltecas tras el apoyo otorgado en la conquista de México. Este ayuntamiento gozaba de una importante autonomía sustentada en diversos privilegios concedidos por la Corona española, entre ellos la posesión de todas las tierras de la provincia como parte de su patrimonio, la inaplicabilidad de la encomienda y los servicios personales y la comunicación directa con el Rey para apelar decisiones tomadas por autoridades menores. ${ }^{18}$

Y si bien de manera esquemática el párrafo anterior sintetiza el por qué del autogobierno tlaxcalteca y algunos de sus principales elementos a partir del dominio español, Andrea Martínez Baracs ofrece una explicación más profunda de la singularidad de la provincia de Tlaxcala en el período colonial. ${ }^{19}$ Dos son sus elementos esenciales en opinión de la autora: la autonomía que mantuvo Tlaxcala respecto al imperio Azteca en la época prehispánica y la defensa permanente del autogobierno indio en el período colonial producto de las prerrogativas otorgadas por la corona española.

18 La autonomía hace referencia esencialmente a los márgenes de autogobierno que gozó el ayuntamiento indio en el marco del Antiguo Régimen, bajo los privilegios que le fueron otorgados por la corona española. La palabra autonomía es una traducción semántica contemporánea, que denota niveles de independencia y autogobierno de una corporación.

19 MARTÍNEZ BARACS, Andrea, Un gobierno de indios: Tlaxcala, 1519-175o, México, FCEFideicomiso Colegio de Historia de Tlaxcala-CIESAS, 2008. 
Este segundo punto fue una constante que logró mantener la autonomía de Tlaxcala, dentro de los marcos coloniales, en relación a los intentos externos de minimizarla. Por otra parte, la defensa del ayuntamiento indio como única corporación de gobierno en la provincia, significó frenar los intentos de diversos pueblos sujetos por obtener un estatus de autogobierno. De ambos fenómenos saldría triunfante el gobierno indio evitando la disolución territorial de Tlaxcala en términos políticos y administrativos, y la pérdida de sus privilegios.

La peculiaridad tlaxcalteca, de acuerdo a Martínez Baracs, consiste pues en su éxito para mantener la unión política territorial y evitar la desaparición como cuerpo político en un largo plazo, con ello se sostuvo "... como un gobierno indio provincial, esto es, un auténtico gobierno indígena que consigue ser a la vez parte fundamental del gobierno de una provincia novohispana." ${ }^{20}$

En una línea de estudio similar, para explicar la singularidad de Tlaxcala, recientemente el historiador José María Portillo Valdés ha desarrollado la idea de la identidad foral como un eje que fundamentó la existencia de Tlaxcala como provincia novohispana. ${ }^{21}$ Dicha identidad tuvo como atributos a los privilegios, un gobierno y un territorio; elementos que se cumplen en Tlaxcala, provincia que fue dotada de prerrogativas al incorporarse a la monarquía española, un cuerpo político gobernante en la figura de un ayuntamiento indio con exclusividad para los caciques (acompañado por un gobernador español) y una jurisdicción territorial cuyo centro fue la ciudad de Tlaxcala. En opinión de Portillo la operatividad y fuerza de dicha identidad foral, puede verse particularmente en el período que va de las Reformas Borbónicas a la primera experiencia republicana en México, ya que el gobierno indio utilizó el discurso sobre los privilegios en el tránsito de un mundo con valores del Antiguo Régimen a uno moderno en términos políticos, con la finalidad de defender su existencia como cuerpo político.

En efecto, en el marco de las Reformas Borbónicas, en 1787 la autonomía de Tlaxcala fue cuestionada con la anexión de la provincia a la Intendencia de Puebla, si bien tras diversas reclamaciones hechas por el ayuntamiento indio y el gobernador

\footnotetext{
20 Ibid., p. 25.

${ }^{21}$ PORTILLO VALDÉS, José M., Fuero Indio. Tlaxcala y la identidad territorial entre la monarquía imperial y la república nacional, 1787-1824, México, El Colegio de México-Instituto de Investigaciones Dr. José María Luis Mora-CONACYT, 2015.
} 
español con el fin de mantener la continuidad de un régimen independiente sustentado en los privilegios, en 1793 el Rey de España decidió separar a Tlaxcala de la Intendencia poblana y otorgarle el status de gobierno político y militar, encabezado por un gobernador español, y reconocido por el Monarca y las autoridades virreinales como un régimen autónomo. Lo anterior le permitió al ayuntamiento indio subsistir con los derechos de Antiguo Régimen que le habían sido otorgados siglos atrás, ya que al ser reconocida Tlaxcala como gobierno político y militar, el ayuntamiento allí existente cobraba vigencia en tanto corporación de gobierno.

Cabe hacer notar aquí un par de cuestiones. Por un lado que con la aplicación de las Reformas Borbónicas, proceso de centralización y control político, administrativo y económico, aumentó el rechazo a los privilegios que habían estructurado el sistema colonial en cuanto al gobierno y la política, si bien por otra parte provocó una amplia defensa de los derechos otorgados previamente por la Corona española. Como señala Rojas:

"Esta reactivación se dio dentro del marco de la cultura política de que disponían, la del antiguo régimen, la de los privilegios. Así mientras, la corona aumentaba su rechazo a los privilegios y a los fueros, las repúblicas y en general las corporaciones los defendieron.”22

La defensa de la autonomía de gobierno en Tlaxcala se reavivó también años después con el inicio de la guerra insurgente en 1810, cuando se acentuó la supeditación militar y política a jefaturas militares en la Nueva España a jefaturas militares, con la vigencia de la Instrucción para el gobierno económico-político de las provincias, emitida en 1813 por el Virrey Félix María Calleja. De acuerdo al artículo V del capítulo III, de dicha Instrucción, en las plazas amenazadas por la insurrección y "en evidente desorden público", el gobierno que tuviera a su cargo la seguridad interior y exterior de la provincia estaría en la eventualidad no sólo de intervenir en decisiones del ámbito militar sino del terreno político. Esto significaba que al pertenecer Tlaxcala al territorio que resguardaba militarmente la comandancia del Ejército del Sur, localizada en Puebla, el comandante militar de aquélla podía ejercer también el mando político ante la amenaza de la insurgencia, lo que resultaba sin lugar a dudas lesivo para los intereses del ayuntamiento tlaxcalteca y del gobierno político y militar.

${ }^{22}$ ROJAS, Beatriz, "República de españoles: antiguo régimen y privilegios", Secuencia, Instituto de Investigaciones Dr. José María Luis Mora, núm. 53, mayo-agosto 2002, pp. 7-48. 
Precisamente esta fue la circunstancia que protagonizó el primer ayuntamiento constitucional de la ciudad de Tlaxcala, y que le acarrearía diversos conflictos con el comandante del Ejército del Sur. Como se sabe, la Constitución española de Cádiz estuvo vigente entre 1812 y 1814, años en los cuales fue erigido formalmente un ayuntamiento constitucional, desapareciendo así, formalmente, el cabildo indio y sus privilegios. ${ }^{23}$ Las elecciones para conformar la corporación gaditana a fines de 1812, resultaron favorables para un grupo mestizo y criollo con intereses económicos locales, que aprovechó abiertamente la coyuntura gaditana para acceder como ciudadanos al gobierno de su territorio, desplazando ampliamente a los caciques indígenas del extinto cabildo indio. ${ }^{24}$

Ahora bien, en 1814 este grupo mestizo y criollo, en su condición de integrante del ayuntamiento constitucional de Tlaxcala, protagonizó un conflicto con el comandante del Ejército del Sur, quien nombró a un gobernador sustituto, ante la licencia por enfermedad solicitada por el gobernador político y militar de la provincia. El ayuntamiento mantuvo una abundante correspondencia con el Virrey Félix María Calleja para tratar de resolver a su favor la designación del gobierno sustituto, ya que de acuerdo a las reglas gaditanas, era en el primer alcalde del ayuntamiento de la capital provincial en quien recaía el gobierno político por la ausencia del gobernador titular. ${ }^{25} \mathrm{Y}$ si bien Calleja reconocía la razón legal esgrimida por el ayuntamiento de la ciudad de Tlaxcala, por otra parte permitió de facto que el gobernador sustituto, designado por la autoridad militar poblana, actuara en los ámbitos de gobierno como militar. Incluso los miembros del ayuntamiento, para no dejar duda sobre su independencia de las autoridades de Puebla, hacían referencia a que si bien Tlaxcala había pertenecido a la Intendencia de Puebla entre 1787 y 1793 , en este último año habían recuperado el reconocimiento de la Corona española como provincia independiente, con un gobierno autónomo.

\footnotetext{
23 BUSTAMANTE LÓPEZ, Carlos, "El conflicto institucional y político por la autonomía en el primer ayuntamiento constitucional de la ciudad de Tlaxcala", Osvaldo ROMERO, Magdalena SAM y Carlos BUSTAMANTE, Autonomía, violencia y actores sociales en Tlaxcala, Puebla e Hidalgo, México, Universidad Autónoma de Tlaxcala, 2009, pp. 13-26.

24 ROBINS, Wayne, "Cambio y continuidad en el ayuntamiento de la ciudad de Tlaxcala, 1810-1825", Historia y grafía, Universidad Iberoamericana, 1996, núm. 6, pp. 87-112; BUVE, Raymond, "Cádiz y el debate sobre el estatus de una provincia mexicana, Tlaxcala entre 1780 y 1850 ", Antonio ESCOBAR, Romana FALCÓN y Raymond BUVE (comp.), Pueblos, comunidades y municipios frente a los proyectos modernizadores en América Latina, siglo XIX, CEDLA-El Colegio de San Luis Potosí, 2002, pp. 9-27.

${ }_{25}$ BUSTAMANTE LÓPEZ, Carlos, ob. cit.
} 
Como lo ha señalado Juan Ortiz, el Virrey Calleja, quien no estaba de acuerdo con las reformas constitucionales de Cádiz, entendió la necesidad formal de obedecer la norma, pero buscando no afectar a la autoridad virreinal. ${ }^{26}$ La estrategia fue acatar las disposiciones de Cádiz que fortalecían la autoridad del Virrey y actuar de manera flexible en aquellas que les restaban fuerza. Así aunque Calleja dio la razón legal al ayuntamiento de Tlaxcala para hacerse cargo del gobierno, en la práctica el gobernador sustituto nombrado por el comandante del Ejército del Sur actuó más allá del terreno meramente militar, y con ello se contrarrestaron las aspiraciones de autogobierno de mestizos y criollos en el marco de las reformas de Cádiz. A final de cuentas éstos buscaban preservar su autonomía no sólo como ayuntamiento de la ciudad de Tlaxcala, sino incluso tratando de reproducir a nivel provincial, ahora bajos las reglas de Cádiz, el peso específico que había tenido el Cabildo indio siglo atrás.

\section{Los miembros del ayuntamiento indio de Tlaxcala, 1815-1820}

A fines de 1814 dejó de tener vigencia la constitución gaditana y nuevamente las estructuras corporativas del Antiguo Régimen funcionaban como gobiernos de la sociedad novohispana. De acuerdo con Robins, en 1815 fue reinstalado el ayuntamiento indio tal como estaba constituido en 1808. Este autor indica que los miembros fallecidos de este último se reemplazaron "... antes de proceder... a la elección de nuevas autoridades en 1815”.27 La misma corporación continuó en 1816 y probablemente en 1817. Para 1818 se verificó la elección, designándose nuevos miembros con base en el sistema que se practicaba desde el siglo XVI. Robins refiere que el ayuntamiento de 1818 fue reelegido el siguiente año. ${ }^{28}$ Este señalamiento, se confirma tras la revisión del Acta de Cabildo del 1 de enero de 1819, pues en ella se indica que se hizo una consulta al Virrey en diciembre de 1818, para que se aprobara la reelección tanto de los miembros del ayuntamiento, como de todos los oficiales de

26 ORTIZ, Juan, "Un gobierno popular para la ciudad de México. El ayuntamiento constitucional de 1813-1814", Virginia GUEDEA, (coord.), La independencia de México y el proceso autonomista novohispano, 1808-1824. México, UNAM-Instituto de Investigaciones Dr. José María Luis Mora, 2001, pp. 117-134

${ }_{27}$ ROBINS, Wayne, "Cambio y continuidad en el ayuntamiento de la ciudad de Tlaxcala, 1810-1825", Historia y grafía, México, Universidad Iberoamericana, núm. 6, 1996, p. 97.

28 Ibid., p. 102. 
república de la provincia; lo cual fue aprobado "siempre y que no haya oposición por parte de los electores..." 29

Aunque para el caso del ayuntamiento indio de Tlaxcala no se ha localizado la información que dé cuenta sobre los pormenores de los procesos electorales de 1815 a 1820, ha sido posible obtener los nombres de los miembros de la corporación, lo que puede dar una idea de la continuidad del personal político en estos años.30 En el ayuntamiento indio de 1816 hay al menos ocho miembros que también lo fueron en el año anterior, si bien los otros cuatro funcionarios de 1816 no tienen este mismo antecedente. Por lo que respecta al señalamiento de Robins en torno al ayuntamiento de 1817, sólo se puede decir que la mitad de los miembros lo habían sido en 1816, y de ellos tres también fueron capitulares de esa institución en 1815. Es importante mencionar que tres de los miembros del ayuntamiento de 1817, como era el caso de Bernardino de Salazar, Diego Phelipe de Lira y Francisco Torres Torrija, no habían ocupado antes algún puesto similar. Por otra parte, en cuanto a la continuidad en el ayuntamiento de 1818 y 1819, es importante acotar que al menos seis de los 23 miembros de 1819, no fueron personal de la corporación en 1818. De hecho, los 17 miembros que sí formaron parte de los ayuntamientos considerados en esos dos años, ocuparon prácticamente los mismos puestos en ambos. Si consideramos ahora el ayuntamiento de 1820 , elegido a finales de 1819, tenemos que de los 21 miembros, 13 de ellos estuvieron en 1818 y 1819, mientras que 5 lo fueron sólo en 1819, y 3 por primera vez eran miembros de la institución.

En su conjunto, los datos anteriores indican que se trata precisamente de ayuntamientos reelectos en el ámbito del sistema colonial, con actores identificados plenamente en los procedimientos habituales de elección entre miembros de caciques y nobles indígenas. Cabe señalar que el restablecimiento de la Constitución de Cádiz no se verificó sino hasta mayo de 1820, y la elección de ayuntamientos en Tlaxcala no

\footnotetext{
${ }^{29}$ Archivo Histórico del Estado de Tlaxcala (AHET), Fondo Archivo Municipal del Tlaxcala (FAMT), c. 5, s/f, diciembre de 1818, "Al ayuntamiento de Tlaxcala" y c. 5, s/exp., fs. 3-4, 1 de enero de 1819, "Acta de elección de miembros del ayuntamiento de Tlaxcala".

${ }^{\circ}$ FLORES HERNÁNDEZ, Lorena, GARCÍA PÉREZ, Rosalina y ROLDAN MORALES, Lehidy, De provincia a territorio: Tlaxcala a finales de la colonia y primeras décadas del siglo XIX, México, Tesis de Licenciatura en Historia, Universidad Autónoma de Tlaxcala, 1998.
} 
comenzó a celebrarse hasta julio, por lo que al menos durante el primer semestre de ese año gobernó un ayuntamiento indio elegido a finales del año anterior. ${ }^{31}$

\section{Los argumentos de los privilegios, $\mathbf{1 8 1 5 - 1 8 1 7}$}

El 12 de diciembre de 1815, el coronel Agustín González del Campillo, gobernador político y militar de Tlaxcala, escribió un oficio al Virrey Félix María Calleja, indicándole que le era imposible satisfacer el requerimiento de 100 hombres para la lucha contra la insurgencia, ya que la fuerza existente en Tlaxcala, apenas era suficiente para defenderla. También refería que muchos habitantes habían abandonado la provincia y que todos los hombres entre 16 y 60 años ya habían formado parte de las compañías realistas. ${ }^{22}$ Un día después, el 13 de diciembre, pero en este caso el ayuntamiento indio de Tlaxcala, escribió un oficio al citado Virrey en el que hacía referencia a la solicitud de que 100 hombres del Regimiento Provincial de Tlaxcala salieran de la ciudad.33 El reclamo del ayuntamiento era que los generales del Ejército del Sur, cuya comandancia estaba situada en la ciudad de Puebla, no habían atendido la defensa de la provincia de Tlaxcala, lo que finalmente era notorio en la situación de ruina de ésta hacia 1815.34

Ahora bien, el ayuntamiento también señalaba que el Ejército del Sur veía con desprecio al gobernador político y militar de Tlaxcala, lo que explicaba que no se destacaran oportunamente militares para la protección de la provincia. Además, llama la atención que se hace referencia a los privilegios del ayuntamiento indio, ya que con la actitud de la comandancia realista, sucedía que se estaban “...vulnerando sus antiguos privilegios, y vexandola de un modo que en tiempos anteriores no se había experimentado".35

Es importante hacer un paréntesis aquí para recordar que en este momento la provincia de Tlaxcala continuaba bajo la subordinación política y militar de la

${ }^{31}$ Véase Archivo General de la Nación, México (AGN), Ramo Operaciones de Guerra (ROP), vol. 31, fs. 284-293, julio de 1820, "Juntas de Parroquia, elecciones de ayuntamiento en San Luis Apizaco y San Salvador Zompantepec".

$3^{2}$ Véase AGN, ROP, vol. 956, fs. 100-101, 12 de diciembre de 1815, "A. González del Campillo al Virrey Calleja”.

33 Ibid, f. 105, diciembre de 1815, "El ayuntamiento de Tlaxcala al Virrey Félix María Calleja".

34 En enero de 1815, el ayuntamiento había desarrollado una fuerte actividad frente a las autoridades de la comandancia del Ejército del Sur, con el fin de obtener 100 fusiles para la defensa de la ciudad de Tlaxcala. Las armas habían sido prometidas por el Virrey. Véanse diversos oficios en AHET, FAMT, c. 4, exp. 4. fs. 158-165.

35 AGN, ROP, vol. 956, f. 105, diciembre de 1815 . 
comandancia del Ejército del Sur, ubicada en la ciudad de Puebla, dependencia sustentada en la Instrucción para el gobierno económico-político de las provincias de junio 1813, que posibilitaba esta situación en plazas amenazadas por la insurgencia en la Nueva España. Esto explica las reiteradas peticiones del ayuntamiento y el gobernador político y militar de Tlaxcala en los siguientes cinco años, para que se devolviera la jurisdicción en el ámbito político y militar, toda vez que se veían transgredidos sus privilegios y autonomía. ${ }^{36}$

Habría que preguntarse qué antiguos privilegios y vejaciones señalaba el ayuntamiento indio de Tlaxcala. Primero que nada, sus miembros indicaban la fidelidad de la ciudad desde la conquista, la cual se había refrendado a favor de la corona española ante la situación militar de confrontación entre insurgentes y realistas, y que desde 1811 se había resentido en la provincia de Tlaxcala a través de las incursiones de la insurgencia para obtener pertrechos.

Para continuar con su argumentación, el ayuntamiento de Tlaxcala ejemplificó la pérdida de Huamantla en manos de la insurgencia liderada por Juan Francisco Osorno.37 A final de cuentas, señalaba, la situación se extendía a las haciendas y ranchos vecinos, ya que eran abandonados por sus propietarios y habitantes. ${ }^{38} \mathrm{Sin}$ embargo, el ayuntamiento indio también culpaba de dicha situación a las divisiones realistas, cuyos jefes con "el mando absoluto" ejercían una autoridad sin límites, imponiendo impuestos y contribuciones a los habitantes de la provincia. Y son precisamente los nativos de Tlaxcala que han vivido dicha situación, señalaba la corporación, quienes pedían que el gobernador y el ayuntamiento pusieran el remedio. Además, ambas instancias eran los primeros en lamentar que no pudieran

\footnotetext{
${ }_{36}$ Para 1815 y principios de 1816 las fuerzas realistas controlaban ya diversas poblaciones y localidades, entre ellas Tlaxcala. La insurgencia se había replegado hacia las zonas montañosas de la Mixteca y la sierra norte, ambas localizadas en Puebla. Este dato indica que en realidad la provincia de Tlaxcala ya no era amenazada de forma importante por las fuerzas insurgentes entre 1815 y 1820 . Aun así, la subordinación de Tlaxcala a la comandancia poblana, al menos en lo militar, continuó incluso años después de estar nuevamente vigente la Constitución de Cádiz en mayo de 1820. Véase BARBOSA RAMÍREZ, Jesús, La respuesta del ejército realista al movimiento de independencia en la región poblana, 1808-1821, Tesis de Licenciatura en Historia, Benemérita Universidad Autónoma de Puebla, 1993, pp. 77-78.

37 Meses después, en abril de 1816, el cura Antonio María Villaseñor de Santa Cruz, Tlaxcala, realizó viajes al norte de la provincia, concretamente a Tlaxco, para arreglar las condiciones del indulto de Osorno y otros rebeldes que operaban en Tlaxcala, sin éxito. Véase AGN, ROP, vol. 956, fs. 89, 94, 95 y 112.

$3^{8}$ Ibid.
} 
hacer algo para evitarlo. $\mathrm{Y}$ es a partir de aquí, que el ayuntamiento comienza a argumentar sobre esos privilegios que habían sido "vejados y vulnerados".

La corporación india se preguntaba por qué sucedía lo anterior si el gobernador militar y político lo era de la provincia de Tlaxcala por instrucciones reales, además de estar ésta absolutamente separada de Puebla desde 1793. Era tal el grado de incumplimiento de los privilegios, que incluso jefes de divisiones del Ejército del Sur, del mismo rango del gobernador, daban órdenes a éste. 39 Los males causados a la provincia y su gobierno eran evidentes para el ayuntamiento:

"es perjudicial a todo el Gobierno, que por no haberse puesto una División regular en esta Plaza, la rebelión haya tomado tanto cuerpo en sus inmediaciones: es perjudicial, que por lo mismo perseguido los Labradores por los reveldes hayan algunos abandonado sus Fincas con lo qual se ha destruido el comercio, y las alcavalas y contribuciones no han podido subsistir baxo el pie que estaban." 40

Era claro para el ayuntamiento indio de Tlaxcala y el gobernador político y militar, que el Virrey Calleja podía cambiar la situación de subordinación militar y de gobierno, en tanto se argumentaba con base en los privilegios tlaxcaltecas y la separación de la Intendencia de Puebla, derivando de ello un gobierno provincial con autoridad en los ámbitos que intitulaban la gubernatura. ${ }^{41}$ Se pedía concretamente que el gobernador político y militar de Tlaxcala fuera nombrado comandante general de la provincia. ${ }^{2}$ De suceder esto, el ayuntamiento prometía tener una fuerza militar que, con la cooperación de los habitantes de Tlaxcala, lograría mantener alejados a los rebeldes insurgentes.

Es significativo que aparentemente no hubo respuesta alguna del Virrey Calleja, no obstante existen dos oficios de enero de 1816 de la comandancia general del Ejército del Sur, en los que al menos en uno de éstos parecería que era conocido el amplio oficio enviado al Virrey Calleja por parte de las autoridades tlaxcaltecas. 43

\footnotetext{
39 AGN, ROP, vol. 956, f. 106.

40 Ibid., f. 107.

${ }^{41}$ Por ejemplo, en el mismo oficio se citaba el caso de las Juntas de contribuciones de impuestos, que por la Ordenanza del 28 de diciembre de 1814, la Provincia de Tlaxcala debía recaudarlas y entregarlas a la Comandancia general de Puebla.

42 AGN, ROP, vol. 956, f. 108.

43 Ibid., ambos del 9 de enero de 1816.
} 
En el primero de ellos sólo se indica que el ayuntamiento de Tlaxcala debía remitir a los desertores a Puebla, para ser integrados a las fuerzas realistas. ${ }^{44}$ En cuanto al segundo, firmado por el comandante general del Ejército del Sur, hace referencia al oficio del 13 de diciembre enviado por el ayuntamiento, señalando que conocía por éste las dificultades para enviar a los 100 hombres requeridos para Puebla. Se limita a indicar al gobernador político y militar que envíe a los hombres disponibles, y añade que Tlaxcala debe demostrar su fidelidad al Rey remitiendo el mayor número posible para lograr la derrota de los rebeldes de Apan y "otras demarcaciones". 45 Es de notar que la respuesta del comandante general del Ejército del Sur ignora por completo la argumentación del ayuntamiento indio sobre los privilegios de su separación de Puebla desde 1793, así como la autoridad militar del gobernador de Tlaxcala, otorgada con la creación en ese mismo año de la gubernatura política y militar. Y tampoco se dice cuáles serían las razones por las que, al menos desde el punto de vista de la comandancia, no podían estar "vigentes" los privilegios tlaxcaltecas de 1793 .

Un año después, el 2 de diciembre de 1816, el gobernador político y militar de Tlaxcala envió al nuevo Virrey, Juan Ruiz de Apodaca, una carta en donde le solicitaba el restablecimiento en su gobierno de los ramos de justicia y hacienda. 46 Ámbitos que sin duda habían sido nulificados como actos de gobierno, pues recuérdese que la comandancia poblana tenía lo político y militar bajo su jurisdicción, con base en el argumento de que continuaba la inestabilidad militar. González de Campillo aludía al hecho de que se había conseguido la pacificación de la provincia y, en efecto, para el año de 1817, no se tienen registros de combates entre insurgentes y realistas en Tlaxcala. 47 En este sentido es que parece comprenderse su propuesta de retomar en su mando dos sensibles aspectos del gobierno político y militar. También señalaba González del Campillo que organizaría destacamentos militares con la aprobación de la comandancia general del Ejército del Sur, e incluso proponía el arreglo de caminos con la imposición de contribuciones a coches, caballos, mulas y

\footnotetext{
44 Ibid., f. 129, 9 de enero de 1816, “José Moreno al gobernador de Tlaxcala”. En abril de este mismo año, el comandante del Regimiento provincial de Tlaxcala, enviaba una solicitud para que los desertores de esta fuerza militar no salieran de la Provincia, dada la poca cantidad de efectivos para la defensa. Véase Ibid., f. 84.

45 Ibid., f. 129, 9 de enero de 1816, "Comandante general del sur al gobernador de Tlaxcala".

46 Ibid., f. 91, 2 de diciembre de 1816, "Agustín González del Campillo al Virrey de Apodaca"

47 BARBOSA RAMÍREZ, Jesús, La respuesta..., ob. cit., p. 79.
} 
burros, para no afectar a las haciendas. Finalmente pedía la aprobación del Virrey para sus planes de gobierno.

No obstante, en el mismo oficio, Ciriaco del Llano, comandante general del Ejército del Sur, escribió una nota donde señalaba que le parecía improcedente la propuesta de González del Campillo relativa a la organización de dos compañías realistas, ya que éste había fracasado anteriormente en mantener a la única fuerza militar que existía en Tlaxcala. Por otra parte, consideraba que era suficiente tener gente armada en las haciendas y de esta forma conservar la defensa militar, tal y como se había hecho en San Martín Texmelucan, Puebla. En cuanto a los impuestos que quería cobrar el gobernador político y militar de Tlaxcala, consideraba Del Llano que acabarían aún más con la ya deteriorada economía tlaxcalteca. $4^{8}$ Como puede verse, es evidente que constantemente era negada la posibilidad de ejercer tareas de gobierno. Pero no sólo eso, ya que González del Campillo también pretendía llevar a cabo acciones de tipo militar e intentar solventar compañías militares con recursos propios, y de esta manera recuperar el control del ámbito castrense y ganar con ello autonomía.

Para abril de 1817 González del Campillo llevó a cabo un nuevo intento de evadir la tutela de Puebla en lo político y militar. La oportunidad se presentó cuando, en marzo de ese año, el Intendente de Puebla informó a aquél que aparentemente había sido suprimida la comandancia del Ejército del Sur. La pregunta de González del Campillo al Virrey Apodaca era directa sobre si debía o no "... reconocer al señor Gobernador Intendente de Puebla como Comandante general de esta Provincia..." 49 Sin embargo, en realidad el Ejército del Sur no fue suprimido sino varios años después.

Incluso la argumentación que expresaba González del Campillo al Virrey Apodaca, aludía nuevamente a la real cédula que desde 1793 independizó a Tlaxcala en lo político y militar de la Intendencia de Puebla. Sin embargo, en mayo de 1817 se le respondió (presumiblemente el Virrey) a González del Campillo, que si podía sostener a una fuerza militar sin recurrir a la comandancia general de Puebla, entonces quedaría a su mando el control de dicho contingente y las actividades de

49 Ibid., f. 130, 19 de abril de 1817, “Agustín González del Campillo al Virrey Juan Ruiz de Apodaca”. 
éste en la provincia de Tlaxcala.50 Finalmente, se argumentaba que en realidad se dudaba mucho que esto sucediera, concluyéndose que el gobierno de Tlaxcala debería seguir dependiendo del mando militar de la comandancia poblana, en los términos que hasta ese momento estaban vigentes..$^{11}$ Para las autoridades virreinales, parecería que no se violentaba nada de lo que el Rey había decidido en torno a los privilegios de la provincia de Tlaxcala, particularmente en lo político y militar, sin embargo la situación prevaleciente justificaba la subordinación producto de las circunstancias de guerra existentes. 52

Para 1817 los enfrentamientos entre insurgentes y realistas habían disminuido considerablemente en el área que estaba bajo jurisdicción militar de la comandancia militar del Ejército del Sur; por lo que toca a la provincia de Tlaxcala, se encontraba en pleno control de esta fuerza novohispana. En todo caso, cabe recordar que formalmente la Instrucción para el gobierno económico-político de las Provincias de 1813 sería el sustento normativo del control sobre los ámbitos militar y político de la provincia, además de que mantener al gobierno tlaxcalteca bajo la supeditación de la comandancia poblana con el argumento de las amenazas insurgentes, y la vigencia de la Instrucción de 1813 era una manera de ejercer un control político sobre grupos locales y regionales y evitar con ello, hasta donde fuera posible, el fraccionamiento del virreinato. 53

\section{Los argumentos militares, $1817-1818$}

Para mediados de 1817 el gobernador político y militar de Tlaxcala tomaba una posición distinta en relación a las constantes peticiones y solicitudes que, durante los años previos, llevó a cabo para que se le diera el control político y militar de la provincia. Concretamente utilizaba un decreto real en relación a la autoridad militar de los gobernadores en sus plazas de residencia, lo que implicaba tener la capacidad

$5^{0}$ Ibid., f. 128, mayo de 1817, "Al gobernador político y militar de Tlaxcala".

${ }^{51}$ En 1817 la Gaceta del Gobierno de México del 28 de junio, publicaba que una compañía de Tlaxcala actuaba fuera de la provincia, lo que muestra la forma en que se decidía sobre la actividad militar de fuerzas asentadas para la defensa de Tlaxcala, aun a pesar de las continuas cartas donde se manifestaba la necesidad de que quedaran en resguardo de ésta. Véase AGN, ROP, vol. 956, fs. 124126.

$5^{2}$ Los continuos reveses contra la petición de devolver al gobierno político y militar de Tlaxcala sus derechos de gobierno, no impidieron que ante los triunfos de los realistas se pronunciaran las autoridades tlaxcaltecas con felicitaciones extensas al Virrey y misas de celebración. Véase Ibid., fs. 115-188 por la aprehensión de Francisco Javier Mina en 1817 y AGN, ROP, vol. 31, fs. 226-228, por la recuperación realista del Fuerte de San Gregorio en Guanajuato en 1818.

53 ORTIZ, Juan, Guerra..., ob. cit. 
de decidir en esta materia, y reintegrar así el control militar. En julio, enviaba un carta al Virrey Apodaca, en donde le hacía notar que el Rey, en un decreto del 28 de diciembre de 1816, y publicado en la Gaceta de México, había autorizado que los gobernadores intervinieran en la revistas a las fuerzas militares destacadas en sus plazas. Esto implicaba el santo y orden diario, la expedición de pasaportes, licencias temporales y autorización de documentos, y además, como estaba a su cargo la seguridad de las plazas donde residían, tenían el mando absoluto de las tropas para decidir la forma de utilizarlas. Por los argumentos anteriores, y dado que González del Campillo poseía el nombramiento de gobernador militar en Tlaxcala, le solicitaba al Virrey que tomara una decisión al respecto; sin embargo, al parecer este último nunca lo hizo. 54

Con una nueva argumentación, dada la renuncia del coronel de milicias provinciales de la ciudad de Tlaxcala, en marzo de 1818 el ayuntamiento indio envió al Virrey Juan Ruiz de Apodaca una misiva en la que argumentaba tener el privilegio de nombrar al nuevo encargado de las milicias de la ciudad.55 En la carta se transcribía el decreto del Rey del 25 de febrero de 1795, que resolvía a favor del ayuntamiento la propuesta de los empleos de coronel, teniente coronel y oficiales de fusileros de la milicia local, quedando en el subinspector general, la definición de los cargos de sargento mayor y ayudantes. Así, se dejaba al ayuntamiento indio la decisión del primer y segundo jefe de la milicia. La respuesta del Virrey Apodaca fue la de aceptar la designación del encargado interino del regimiento de la ciudad de Tlaxcala, que ya había hecho la corporación tlaxcalteca. Sin embargo, recordaba al ayuntamiento que debido a las circunstancias de guerra, era deseable que las designaciones fueran hechas por militares de la misma clase o mayor rango, con méritos suficientes para garantizar una efectiva lucha contra la insurgencia. $Y$ aunque reconocía las prerrogativas de los ayuntamientos, concluía diciendo que las circunstancias de guerra establecían un proceder distinto. ${ }^{5}$

Se puede decir que la posición, tanto del gobernador político y militar de Tlaxcala como del ayuntamiento indio, siempre fue en términos legalistas, pero utilizando en este marco las posibilidades que les permitieran ejercer un espacio de

\footnotetext{
54 AGN, ROP, vol. 956, f. 122,19 de julio de 1817, "Agustín González del Campillo al Virrey Apodaca”. 55 Ibid., vol. 31, fs. 238-240, 16 de marzo de 1818, "Cabildo de Tlaxcala al virrey Apodaca".

${ }^{56}$ AHET, FAMT, c. 5, exp. 15, f. 56, 25 de mayo de 1818, "Apodaca al ayuntamiento de Tlaxcala".
} 
autoridad, sustentado en los privilegios del siglo XVI y en la creación de un gobierno autónomo tlaxcalteca en 1793. También se vuelve a ver el discurso que mantuvieron tanto el Virrey como las autoridades militares poblanas: la situación de guerra como una excepcionalidad que implicaba no dejar las decisiones de gobierno y militares en manos de las autoridades locales, aunque reconociendo que existían y estaban latentes los privilegios y derechos del ayuntamiento indio de Tlaxcala.

\section{Los privilegios, la defensa militar y la ruina económica, 1819-1820}

A fines de 1819, el gobernador González del Campillo realizó un nuevo intento por obtener el control político y militar de la provincia de Tlaxcala, ahora ante el Virrey Conde del Venadito.57 Seguramente, el cambio de autoridad del virreinato fue considerado por aquél como una nueva oportunidad, tras varios años de permanentes solicitudes y tres cambios de Virrey. González del Campillo comenzaba, una vez más, señalando las virtudes políticas y militares de Tlaxcala, las cuales habían sido evidentes desde la conquista. A éstas se sumaban la prudencia y la fidelidad, valores por los que fue: “... acreedora a la benevolencia de nuestros amados Soberanos, y a las gracias y privilegios que con mano liberal le han franqueado, engrandeciéndola y poniéndola sobre el nivel del resto de las demás Ciudades de este vasto y dilatado Reyno".58

Y basándose en estas distinciones solicitaba al Virrey que le fueran restituidos los privilegios. González del Campillo era muy claro al señalar: "que todo dependía y estaba sugeto a su Gobernador; con arreglo a lo que tiene prebenido S.M. por su soberana disposición de 1793, y a lo que reza mi despacho de Gobernador militar y político de toda la Provincia”..59

Los argumentos de González del Campillo hacían referencia a que, si bien las medidas extraordinarias de guerra habían impedido que continuaran vigentes los privilegios de gobierno en Tlaxcala, dichas circunstancias ya habían sido superadas hacia fines de 1819. Para el gobernador de Tlaxcala la situación de ruina en la que se encontraba la provincia, podría cambiarse una vez que se restituyera el gobierno

\footnotetext{
57 AGN, ROP, vol. 956, fs. 132-133, 25 de noviembre de 1819, "Agustín González del Campillo al Virrey Conde del Venadito"

${ }_{58}^{8}$ Ibid.

59 Ibid.
} 
político y militar, ya que éste distribuiría de una forma más equitativa las contribuciones entre las haciendas y las poblaciones. Además se comprometía a resguardar la provincia con fuerzas militares cuya manutención correría a cargo de Tlaxcala. Es interesante hacer notar que González del Campillo recalcó la vigencia de las cédulas reales que fundamentaban el gobierno político y militar en Tlaxcala de 1793, señalando que por las circunstancias de guerra se vieron nulificadas dichas determinaciones de la Corona. ${ }^{60}$

Un par de meses más tarde, en enero de 1820, el gobernador de Tlaxcala escribía nuevamente al Virrey Conde del Venadito. En esta segunda carta y con base en su representación del 25 de noviembre de 1819, solicitaba la independencia militar respecto de la comandancia poblana del Ejército del Sur y, junto con ello, el compromiso de solventar una fuerza militar capaz de defender a la provincia de Tlaxcala sin auxilio de la comandancia citada. ${ }^{61}$ La tan ansiada respuesta llegó en mayo de 1820, justamente cuando la Constitución de Cádiz fue restablecida. Considerando las diversas representaciones hechas el Virrey solicitando restituir el gobierno político y militar en el gobernador de Tlaxcala, el Conde del Venadito accedió previo envío del plan de defensa militar por parte de González del Campillo. ${ }^{62}$ Éste se lo hizo llegar el 29 de mayo, indicándole que contaba con 841 realistas y 170 caballos, localizados a corta distancia de la ciudad de Tlaxcala. En suma: "Los partidos, ...recibirán un gran beneficio con la independencia de esta Provincia de todo otro mando militar y se obiaran las continuas disensiones y competencias, entre una y otra jurisdicción". 63

Para iniciar formalmente la entrega, en octubre de 1820 González del Campillo informaba al Virrey que se había llevado a cabo, desde septiembre, la entrega del punto militar de Tlaxco, por parte del coronel Manuel de la Concha, y la anuencia de

\footnotetext{
6o En enero de 1819 el teniente de la Real Justicia del Partido de Chiautempan, denunciaba que los miembros del ayuntamiento indio intervenían en la impartición de justicia en un ámbito territorial que no les competía, de acuerdo a la Ley 16, título 3 de la Recopilación para los Reinos. Esto pone en evidencia un conflicto motivado por la intención de poner en vigencia los privilegios de la corporación de india. Véase AGN, Ramo Tierras (RT), Vol. 1424, exp. 1, fs. 36-38, 26 de enero de 1819.

${ }^{61}$ AGN, ROP, Vol. 956, f. 134, 18 de enero de 1820, "Agustín González del Campillo al Virrey Conde de Venadito".

62 Ibid., f. 135, 6 de mayo de 1820, "Al Sr. Gobernador de Tlaxcala".

63 Ibid., f. 147-148, 29 de mayo de 1820, "Agustín González del Campillo al Virrey Conde de Venadito". Véase el informe estadístico en extenso elaborado por el gobernador de Tlaxcala en Ibid., f. 149-150, "Estado militar de la provincia de Tlaxcala".
} 
las autoridades de esta población localizada al norte de la provincia. ${ }^{64}$ Sin embargo, y a pesar del restablecimiento de la Constitución de Cádiz en mayo de 1820, los conflictos del gobierno político y militar y el ayuntamiento indio de Tlaxcala con la comandancia del Ejército del Sur, no concluyeron; recién en diciembre de 1822 dejaron de estar subordinadas las autoridades tlaxcaltecas a los militares poblanos.

\section{A manera de conclusiones}

El ayuntamiento indio restaurado en 1815 tras la derogación de la Constitución de Cádiz de 1812 muestra, con su continuidad, que no estaba totalmente acabado como gobierno. No sólo porque la formalidad de la estructura de Antiguo Régimen fue recuperada, sino porque varios de sus antiguos miembros volvieron a ocupar puestos en la corporación, lo que sin lugar a dudas indica la persistencia de un privilegio y del personal político dispuesto a ejercerlo. Esto significó que durante los años de 1815 a 1820, los mestizos y criollos estarían nuevamente relegados de la posibilidad de ser elegidos para ocupar lugares en ese ayuntamiento, y de esa forma orientar desde la corporación las acciones gubernamentales. Como se vio en la sección correspondiente, este sector manifestó durante los dos años gaditanos cobijarse en las normas constitucionales de 1812 y bajo ellas actuar en la defensa de su autonomía.

Facultad que se vio mermada en el plano militar y político ante la aplicación de la Instrucción para el gobierno económico-político de las provincias de 1813, y su continuidad hasta cuando menos 1820. Ello implicó depender de las decisiones emitidas por la comandancia del Ejército del Sur localizada en Puebla, además de imposibilitar la organización de una milicia y la toma de decisiones en el terreno económico. En su conjunto, estos aspectos impidieron que las autoridades de la provincia, tanto el ayuntamiento indio como el constitucional, y asimismo el gobierno político y militar, tuvieran la autonomía suficiente para decidir en aspectos clave que fincarían su autogobierno, y minimizar así la sujeción y el control de mandos novohispanos externos.

Actuando de manera conjunta, el gobierno político y militar y el ayuntamiento indio, manejándose siempre en los canales formales y legales que les otorgaban los

\footnotetext{
64 Ibid., f. 136, 6 de octubre de 1820, "Agustín González del Campillo al Virrey Conde de Venadito".
} 
marcos normativos coloniales, argumentaron su autonomía sustentada en los privilegios del siglo XVI otorgados a la corporación india, y en la conformación del gobierno político y militar de 1793, independiente de la Intendencia de Puebla. La autonomía era requerida para gobernar en el régimen de las normas y reglas de los privilegios de Antiguo Régimen, con el fin de darle continuidad a un modelo político de gobierno proveniente de siglos atrás.

La historiografía novohispana ha puesto recientemente énfasis en la riqueza procesual del periodo 1815-1820, ubicándose el ejemplo desarrollado en el artículo dentro de los casos en los que la reinstalación del absolutismo colonial, si bien sirvió de puente para continuar con procesos de centralización iniciados a fines del siglo XVIII a partir de las Reformas Borbónicas, también reactivó las formas tradicionales de defensa de los privilegios otorgados siglos atrás.

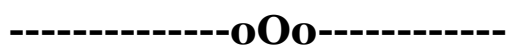

\section{Fuentes}

Archivo Histórico del Estado de Tlaxcala (AHET), Fondo Archivo Municipal de Tlaxcala (FAMT).

Archivo General de la Nación (AGN), Ramo Operaciones de Guerra (ROP) y Ramo Tierras (RT).

\section{Bibliografía}

ANNINO, Antonio y ROJAS, Rafael, La independencia. Los libros de la patria, México, CIDE-FCE, 2008.

ANNINO, Antonio (coord.), La revolución novohispana, 18o8-1821, México, FCE, 2010.

ARCHER, Christon I., "Historia de la guerra: las trayectorias de la historia militar en la época de la independencia de Nueva España”, Alfredo ÁVILA y Virginia GUEDEA, (coord.), La independencia de México. Temas e interpretaciones recientes, México, IIH-UNAM, 2007 (Serie Historia Moderna y Contemporánea, 48). 
-- "La revolución militar de México: estrategia, tácticas y logísticas durante la guerra de Independencia, 1810-1821”, VÁZQUEZ, Josefina (coord.), Interpretaciones de la independencia de México. México, Nueva Imagen, 1997.

-- "En busca de una victoria definitiva: el ejército realista de Nueva España, 18101821", Marta TERÁN y José Antonio SERRANO ORTEGA (ed.), Las guerras de independencia en la América española. México, El Colegio de MichoacánINAH-Universidad Michoacana de San Nicolás de Hidalgo, 2002.

ARRIOJA DIAZ, Luis Roberto, "La experiencia absolutista en una subdelegación novohispana: Villa Alta (Oaxaca)", José Antonio SERRANO ORTEGA (coord.), El sexenio absolutista, los últimos años insurgentes. Nueva España (18141820), México, El Colegio de Michoacán, 2014.

ÁVILA, Alfredo, En nombre de la nación. La formación del gobierno representativo en México (1808-1824), México, CIDE-Taurus, 2002.

ÁVILA, Alfredo y GUEDEA, Virginia (coord.), La independencia de México. Temas e interpretaciones recientes, México, IIH-UNAM, 2007 (Serie Historia Moderna y Contemporánea, 48).

BARBOSA RAMÍREZ, Jesús, La respuesta del ejército realista al movimiento de independencia en la región poblana, 1808-1821, Tesis de Licenciatura en Historia, México, Benemérita Universidad Autónoma de Puebla, 1993.

-- Súbditos, ia las armas! La respuesta del ejército realista al movimiento de Independencia en la región Puebla-Tlaxcala, 1808-1821, México, BUAP, 2009.

BELLINGERI, Marco, "Cabildos en Yucatán. La conformación de las instituciones liberales”, Othón BAÑOS (comp.), Liberalismo, actores y política en Yucatán, México, Universidad Autónoma de Yucatán, 1995.

BERNAL RUIZ, Graciela, "El mandato de su majestad y las circunstancias locales. La reinstalación del absolutismo en San Luis Potosí”, José Antonio SERRANO ORTEGA (coord.), El sexenio absolutista, los últimos años insurgentes. Nueva España (1814-1820), México, El Colegio de Michoacán, 2014.

BUSTAMANTE LÓPEZ, Carlos, Privilegios, conflicto y autonomía en Tlaxcala, 17801824, Tesis de Doctorado en Humanidades-Historia, México, Universidad Autónoma Metropolitana-Iztapalapa, 2008.

-- "El conflicto institucional y político por la autonomía en el primer ayuntamiento constitucional de la ciudad de Tlaxcala", Osvaldo ROMERO, Magdalena SAM y Carlos BUSTAMANTE, Autonomía, violencia y actores sociales en Tlaxcala, Puebla e Hidalgo, México, Universidad Autónoma de Tlaxcala, 2009.

BUVE, Raymond, "Cádiz y el debate sobre el estatus de una provincia mexicana, Tlaxcala entre 1780 y 1850", Antonio ESCOBAR, Romana FALCÓN y Raymond BUVE, (comp.), Pueblos, comunidades y municipios frente a los 
proyectos modernizadores en América Latina, siglo XIX, CEDLA-El Colegio de San Luis Potosí, 2002.

CHUST, Manuel, De la revolución hispana a la revolución española: claves del doceañismo gaditano, 1808-1837, México, CONACYT-Universidad de Zacatecas, 2000 (Lecciones sobre Federalismo, núm. 2).

-- "Legitimidad, representación y soberanía: del doceañismo monárquico al republicanismo federal mexicano", Brian F.CONNAUGHTON, Poder $y$ legitimidad en México en el siglo XIX. Instituciones y Cultura Política, México, UAM-Iztapalapa-CONACYT-Miguel Ángel Porrúa, 2003.

-- "De rebeliones, independencias y, si acaso, revoluciones", Antonio ANNINO (coord.), La revolución novohispana, 1808-1821, México, Fondo de Cultura Económica, 2010.

CHUST, Manuel y FRASQUET, Ivana, "Soberanía hispana, soberanía mexicana: México, 1810-1824", Manuel CHUST (coord.), Doceañismos, constituciones e independencia, La constitución de 1812 y América. España, Fundación MAPFRE, 2006.

CHUST, Manuel y SERRANO, José Antonio, "Un debate actual. Una revisión necesaria", José Antonio SERRANO y Manuel CHUST, (ed.), Debates sobre las independencias iberoamericanas, Madrid, AHILA, (Col. Estudios AHILA, núm. 3), 2007.

DUCEY, Michael T., "Village, nation, and constitution: insurgent politics in Papantla, Veracruz, 1810-1821”, Hispanic American Historical Review, Duke University Press, vol. 79, núm. 3, 1999, pp. 463-493

ESCOBAR, Antonio, "Del gobierno indígena al ayuntamiento constitucional en las huastecas hidalguense y veracruzana, 1780-1853”, Mexican Studies/Estudios Mexicanos, University of California-UNAM, vol. 12, núm. 1, invierno 1996, pp. $1-26$.

ESCOBEDO DELGADO, Martín, "Soberanía y representación. Conceptos fundamentales en el discurso político del Ayuntamiento de Zacatecas (18081821)", José Antonio SERRANO ORTEGA (coord.), El sexenio absolutista, los últimos años insurgentes. Nueva España (1814-1820), México, El Colegio de Michoacán, 2014.

FLORES HERNÁNDEZ, Lorena, GARCÍA PÉREZ, Rosalina y ROLDAN MORALES, Lehidy, De provincia a territorio: Tlaxcala a finales de la colonia y primeras décadas del siglo XIX, Tesis de Licenciatura en Historia, México, Universidad Autónoma de Tlaxcala, 1998.

GUEDEA, Virginia, "La nueva 'historia política' y el proceso de independencia novohispano", Guillermo PALACIOS (coord.), Ensayos sobre la nueva historia política de América Latina, siglo XIX, México, El Colegio de México, 2007. 
-- "La historia política sobre el proceso de independencia", Alfredo ÁVILA y Virginia GUEDEA, (coord.), La independencia de México. Temas e interpretaciones, México, UNAM, 2007.

GUEDEA, Virginia y ÁVILA, Alfredo, "De la independencia nacional a los procesos autonomistas novohispanos: balance de la historiografía reciente" en José Antonio SERRANO y Manuel CHUST, (ed.), Debates sobre las independencias iberoamericanas, Madrid, AHILA, 2007 (Col. Estudios AHILA, núm. 3).

GUARDINO, Peter, Campesinos y política en la formación del estado nacional en México, Guerrero, 180o-1857, México, Stanford University Press-Gobierno del Estado de Guerrero, 1996.

GUZMÁN PÉREZ, Moisés (coord.), Cabildos, repúblicas y ayuntamientos constitucionales en la independencia de México, México, Instituto de Investigaciones Históricas de la Universidad Michoacana de San Nicolás de Hidalgo-Gobierno del Estado de Michoacán, 2009.

HAMNETT, Brian, Raíces de la insurgencia en México, Historia regional 1750-1824, México, FCE, 1990.

HERNÁNDEZ CHÁVEZ, Alicia, La tradición republicana del buen gobierno, México, FCE- El Colegio de México, 1993.

JUÁREZ, Carlos, "Un ayuntamiento mexicano ante la guerra de Independencia: El caso de Valladolid de Michoacán, 1810-1821”, Historias, INAH, núm. 32, abrilseptiembre de 1994.

MARTÍNEZ BARACS, Andrea, Un gobierno de indios: Tlaxcala, 1519-1750, México, FCE-Fideicomiso Colegio de Historia de Tlaxcala-CIESAS, 2008.

ORTIZ, Juan, "La guerra de Independencia y la autonomía de los pueblos", VÁZQUEZ, Josefina Zoraida (coord.), Interpretaciones de la independencia de México, México, Nueva Imagen, 1997.

-- Guerra y gobierno. Los pueblos y la Independencia de México, Instituto de Investigaciones Dr. José María Luis Mora-El Colegio de México-Universidad Internacional de Andalucía-Universidad de Sevilla, 1997.

-- "Un gobierno popular para la ciudad de México. El ayuntamiento constitucional de 1813-1814", Virginia GUEDEA (coord.), La independencia de México y el proceso autonomista novohispano, 1808-1824, México, UNAM-Instituto de Investigaciones Dr. José María Luis Mora, 2001.

ORTIZ ESCAMILLA, Juan y SERRANO, Juan Antonio, Ayuntamientos y liberalismo gaditano, México, El Colegio de Michoacán, 2007.

PORTILLO VALDÉS, José M., Fuero Indio. Tlaxcala y la identidad territorial entre la monarquía imperial y la república nacional, 1787-1824, México, El Colegio de México-Instituto de Investigaciones Dr. José María Luis Mora-CONACYT, 2015 . 
ROBINS, Wayne, "Cambio y continuidad en el ayuntamiento de la ciudad de Tlaxcala, 1810-1825”, Historia y grafia, México, Universidad Iberoamericana, 1996, núm. 6.

RODRÍGUEZ O., Jaime E., La independencia de la América española, México, FCEEl Colegio de México, 1998.

-- El proceso de la Independencia de México, México, Instituto de Investigaciones Dr. José María Luis Mora, 1992.

ROJAS, Beatriz, "República de españoles: antiguo régimen y privilegios”, Secuencia, Instituto de Investigaciones Dr. José María Luis Mora, núm. 53, mayo-agosto 2002.

ROJAS, Rafael, La escritura de la independencia. El surgimiento de la opinión pública en México, México, CIDE-Taurus, 2003.

-- "Historiografía de la independencia (siglo XIX)", ANNINO, Antonio y ROJAS, Rafael, La independencia. Los libros de la patria, México, CIDE-FCE, 2008.

SERRANO ORTEGA, José Antonio (coord.), El sexenio absolutista, los últimos años insurgentes. Nueva España (1814-1820), México, El Colegio de Michoacán, 2014 .

SERRANO ORTEGA, José Antonio, "Las herencias ilustradas y gaditanas en tiempos del absolutismo. Nueva España (1814-1819)", José Antonio SERRANO ORTEGA (coord.), El sexenio absolutista, los últimos años insurgentes. Nueva España (1814-1820), México, El Colegio de Michoacán, 2014.

VÁZQUEZ, Josefina Zoraida, "De la crisis monárquica a la independencia (18081821)", Josefina Zoraida VÁZQUEZ (coord.), Interpretaciones de la independencia de México, México, Nueva Imagen, 1997. 